\title{
Self-cleaning and colour-preserving efficiency of photocatalytic concrete: case study of the Jubilee Church in Rome
}

\author{
Dr Luciano Cardellicchio \\ Senior Lecturer in Architectural Technology, University of Kent \\ L.Cardellicchio@Kent.ac.uk
}

\section{Introduction}

The Jubilee Church, also known as Chiesa Dio Padre Misericordioso, is a building located in the south-eastern outskirts of Rome. Three spherical walls, named shells or sails, embody the most distinguishing design feature of the project (Figure 1). The project belongs historically to a specific time marked by an important number of architectural competitions in Europe, where public and private clients demanded design proposals recognisable by iconic features to promote, with a contemporary monumental addition, the redevelopment of post-industrial towns or the gentrification of socially disadvantaged urban districts (Franklin, 2016).

The three sails of the church, constructed between 2001 and 2002, are one of the first building components built with reinforced concrete with self-cleaning photocatalytic cement (Lyall, 2004). This cement, specifically designed for this building and named TX Millenium, features titanium dioxide particles $\left(\mathrm{TiO}_{2}\right)$ within the concrete mix which also includes white aggregates from Carrara marbles to achieve a bright and smooth white finish. The white colour of the sails was one of the most important design features of the church, and so the cement manufacturer customised a bespoke technical solution to achieve it by blending titania particles into the concrete mix. The aim was also to guarantee long-lasting colourpreserving qualities. Titania is photocatalytic because it is able to absorb energy from light, and then use that energy to catalyse the degradation of organic molecules and the oxidation of some inorganic pollutants, like nitrogen oxides (NOx) (Diamanti, et al., 2015) (Anpo, et al., 1984) (Linsebigler, et al., 1995) (Hunger, et al., 2010) (Hüsken, et al., 8-9 October 2007) (Ballari \& Brouwers, 2013) (Turchi \& Ollis, 1990) (Fujishima \& Zhang, 2006) (Anpo, et al., 1985) (Fujishima, et al., 2008) (Hashimoto, et al., 2005) (Hüsken, et al., 2009) (Gao \& Wachs, 1999).

However, despite the use of the colour-preserving cement, in 2018 the author witnessed and documented the accelerated decay of the appearance of the double-curved walls of the sails of the Jubilee Church manifested with black staining all over the concrete (Figure 2) 
(Cardellicchio, 2018). In this general conservation appraisal of the church, an assumption related to a generic failing of the self-cleaning property of the material was made. This study, therefore, aims to verify this assumption, focusing on the underperformance of the concrete surface and examining in detail why the self-cleaning and colour-preserving properties have not met the design requirements in the short-term of the building life.

Although cement with titanium dioxide has been used widely in buildings and applications since the Jubilee Church, this case study is one of the few buildings where titanium dioxide is incorporated within the concrete cast of a load-bearing component and not merely coated on the surface of a façade. The church, therefore, offered the opportunity to test the durability and the effectiveness of this particular application of $\mathrm{TiO}_{2}$ in real conditions, and thereby to overcome the inherent limits of recreating the accelerated ageing process in a controlled environment within laboratories in which the actions of different factors such as wind, rainwater and light irradiation are simulated (Hassan, et al., 2010) (Graziani, et al., 2014) (Zhang, et al., 2007) (Guo, et al., 2016) (Calia, et al., 2016) (Cedillo-González, et al., 2018) (Sassoni, et al., 2018).

This study finds that the ageing pattern of the concrete in the church is triggered by ignoring local environmental conditions (i.e. the composition of the local atmospheric dust) and is aggravated by the geometrical shape of the church's sails. At first, these findings will help to understand how to improve the aesthetic performance of the concrete to increase its durability and reduce the cost of its maintenance. Subsequently, by comparing the results with the general defects of $\mathrm{TiO}_{2}$ façade published in the literature (Chew \& Conejos, 2017), the general contribution of this case study will be discussed.

\section{Construction and mix design}

The development of the Jubilee Church was technically demanding and time-consuming due to the high degree of innovation required in the construction process. While the architect was awarded the design competition for the church in 1994, the building opened only in 2003. While the rest of the liturgical complex is built with traditional construction techniques, the three sails embodied the most challenging aspect of the technical development of the project. The sails were erected by masonry made by precast double-curved concrete blocks each measuring $3 \times 2$ metres. The design challenge was achieved by the bespoke prefabrication procedure specifically designed for these sails and by developing the self-cleaning TX Millenium cement. Each shell was constructed using a different section of the same sphere 
with a radius of 38.5 metres. These sails are closer to each other on the west side, opening up towards the entrance of the building. The concave sides are south-facing, while the convex sides are north-facing.

The geometry of each sail was engineered following a bespoke grid of vertical parallel planes intersecting radial planes. This grid dissected the shells in 358 blocks belonging only to 22 different geometrical families, optimising the number of concrete blocks built by the same formwork. Shell 1 is the smallest and the most external one counting 78 blocks; Shell 2 is the medium one (104 blocks); Shell 3 is the tallest with its 176 blocks.

Each block was precast slotting a reinforcement cage inside of an adaptable formwork where the concrete mix was poured. The elements then were transferred on site and assembled with post-tension steel cables. A travelling crane designed explicitly for this construction laid down each block, one course on top of the other.

For the mix design the concrete needed to be white and be able to preserve its white colour as long as possible. The manufacturer claimed that by adding $\mathrm{TiO}_{2}$ within the cement, 'The building elements such as the precast panels constituting the three large shells of the Jubilee Church can maintain their aesthetic appearance unaltered over time' (Guerrini, 2011). The development of the concrete formulation to be used for the construction of the Jubilee Church was carried out by using a test method based on the photocatalytic degradation of a phenanthraquinone solution $\left(0.1 \mathrm{mg} / \mathrm{cm}^{2}\right)$, employing white cement pastes. After a UV exposure of the treated specimens, rapid restoration of the clean surface was obtained. This self-cleaning property works needing only the requirements of sunlight, oxygen and water (Folli, et al., 2012) and relies on a combination of the following factors:

- The reduction-oxidation reaction of a pollutant is promoted by sunlight (or in general, weak UV light) on the photocatalyst surface (Fujishima, et al., 1999);

- The photo-induced surface hydrophilicity (Tee, et al., 2005) (Wang, et al., 1997) enhances this self-cleaning effect by mobilising dirt and stains through rainwater soaking between the adsorbed substance and the $\mathrm{TiO}_{2}$ surface.

Therefore, the self-cleaning behaviour works when rainwater, soaking between the adsorbed substance and the hydrophilic surface, removes inorganics that cause dirt and stains on building surfaces. In addition to the self-cleaning property, the material has a depolluting effect due to the oxidation of nitrogen oxides (NOx) in the atmosphere to $\mathrm{NO}_{3}-$. 
Other critical elements of the concrete mix for the Jubilee Church were high strength (75 $\mathrm{N} / \mathrm{mm}^{2}$ ) and excellent workability obtained by using the superplasticiser Mapefluid X404 (Table 1). The high strength was due to the complex structural configuration of the shells while the excellent workability was necessary for the dense reinforcement steel cage within each precast block.

\section{Materials and Methods}

This study followed a mixed-mode research method to qualitatively evaluate the ageing pattern of the exposed concrete of the Jubilee Church and subsequently investigate the reasons behind its accelerated decay.

In order to understand the fabrication process of the sails, a literature review was undertaken together with an archival investigation at the Technical Bureau of the Vicariate in Rome (Ufficio Edilizia di Culto). Several articles well documented the construction process of the sails by explaining the pioneering innovation used for them (Baglione, 2003) (Falzetti, 2003) (Mornati, 2017). The author, therefore, was able to gather extensive information related to the design of the concrete mix and the assembly procedures of the precast blocks.

To understand if any maintenance work was operated on the building between its completion date and the time of this study, the author interviewed the Innovation Manager at the cement manufacturer. Over this meeting information regarding an intervention on the concrete surface were collected. In 2006, three years after the building completion, the overall surface of the shells was washed with high-pressurised water and a protective coating was painted over some blocks at the bottom of each shell. Further chemical tests were necessary during this study to confirm the information shared over the interview.

After gathering information on the original construction process and the maintenance work undertaken until the start of this research project, the concrete pathologies at the building scale were mapped and classified with the help of aerial photogrammetric pictures acquired with drone flights. The flights were operated on the $8^{\text {th }}$ of November 2018 with a clear sky, between 12:30 and 13:30. It is worth noting that the use of the drone was necessary due to the geometrical complexity of the building, where some parts are not fully visible either from the ground floor or the roof.

After identifying the concrete pathologies at the building scale, the specific research questions were formulated for further investigation. These questions were: 
1. Why does the concrete on the south-facing convex side shows a different ageing pattern than the north-facing concave sides for every shell?

2. Is the photocatalysis of the $\mathrm{TiO}_{2}$ still active on the surface of the shells?

3. What is the chemical composition of the blackening dust settled on the shells?

4. What is the chemical composition of the protective layer spread during maintenance work in $2006 ?$

In order to answer these questions, nine micro-samples were chosen and tested according to the Table 2. The tests included: Fourier-transform infrared spectroscopy (FTIR), microRaman spectroscopy and X-ray powder diffraction test (XRD). The FTIR spectroscopic investigation allows the qualitative identification of organic and inorganic components of a sample. Through a spectrum where the vibrations of a chemical bond are recorded, it is possible to identify the functional groups of a molecule and thus to identify it. FTIR spectra were recorded on a VERTEX 70 Bruker Optics instrument, spectral range 4000-400 $\mathrm{cm}^{-1}$, resolution $4 \mathrm{~cm}^{-1}$, equipped with a single-reflection diamond Attenuated Total Reflectance (ATR) cell. Raman spectroscopy is a qualitative spectroscopic technique for the characterisation of organic and inorganic molecules. For this study, Raman spectra were recorded using a micro-Raman dispersive spectrometer (SENTERRA, Bruker Optik GmbH) employing a CW diode pumped solid state laser of $20 \mathrm{~mW}$ operating at $532 \mathrm{~nm}$. The splinters sampled are embedded in resin and analysed without grinding. The spectra were recorded by using a $20 \times$ objective with a resolution of $3 \mathrm{~cm}^{-1}$ in the spectral window from 50 to $3700 \mathrm{~cm}^{-1}$.

X-ray powder diffraction is an analytical technique used for phase identification of a crystalline material. The qualitative survey allows the identification of the crystalline components present in a sample, and it is carried out on powders. XRD patterns were acquired using a Philips Analytical PW1830 X-ray diffractometer, equipped with $\mathrm{Cu} \mathrm{K} \alpha$ $(1.54056 \AA)$ radiation, in the $2 \theta$ range from 5 to $80^{\circ}$ with a step size of $0.02^{\circ}$ and a time for step of $3.5 \mathrm{~s}$. The data were collected with an acceleration voltage of $40 \mathrm{kV}$ and an applied current $30 \mathrm{~mA}$.

Colour measurement (UNI EN 15886, 2010) by CIE Lab Portable 3nh NH310 Colorimeter Chroma Meter was carried out to assess the colour-preserving properties of the concrete. Four measurements were carried out on each of the selected panels. Colour characteristics were referred to the CIELab 1976 colour space, through $\mathrm{L}^{*}$, $\mathrm{a}^{*}$ and $\mathrm{b}^{*}$ parameters; namely, 
lightness/darkness, red/green and yellow/blue coordinates, respectively. The panels selected for this study are the same monitored by the cement manufacturer to measure the colour variations between the year 2000 and 2006 (Guerrini, et al., 2007). The colour variations $\left(\Delta \mathrm{E}^{*}\right)$ between the completion of the building and 2018 were therefore calculated as follows:

$$
\Delta \mathrm{E}^{*}=\left[\left(\Delta \mathrm{L}^{*}\right)^{2}+\left(\Delta \mathrm{a}^{*}\right)^{2}+\left(\Delta \mathrm{b}^{*}\right)^{2}\right]^{1 / 2}
$$

Finally, a year-long solar analysis (from November to November) was simulated using a BIM model and a building performance analysis software (Autodesk Revit and Autodesk Insight). This simulation calculated the amount of solar radiation on each block for each shell to highlight the limitation of adopting a photocatalytic material without considering the building orientation first.

\section{Classification of the concrete surface pathology}

As recent images on social media show, the black staining affecting the shells of the Jubilee Church is evident. By comparing these pictures from the archival images taken the year of the building completion, the material deterioration is detectable on the whole convex side and only at the top of the concave side of each shell. A detailed digital photogrammetric survey was then taken on the concrete surface to identify and categorise the material pathologies. By analysing the photogrammetric survey, the following forms of deterioration were identified:

- Chromatic alteration of the surface due to a layer of a protective coat used to increase the water repellence of the concrete in 2006;

- Patina from biological contamination;

- Localised and diffuse chromatic alteration of the concrete surface due to rain dust;

- Horizontal or vertical fissuring with chromatic alteration of the concrete;

- Concrete crazing with a formation of fine random cracks of fissuring. The size of the irregular hexagonal areas enclosed by cracks are no smaller than $15 \mathrm{~mm}$;

- Concrete dusting due to erosion;

- Concrete discolouration.

As the images revealed, three factors triggered the superficial alteration of the white concrete: deposit of rain dust, previous maintenance work and biological attack.

The presence of rain dust is the most evident alteration on the concrete surface (Figure 3). It is evident that the rate of blackening on a horizontal surface is higher than the rate on a 
vertical surface (Brimblecombe \& Grossi, 2004), but for buildings enclosed by non-standard geometries (spherical, ruled surface, Non-uniform rational B-spline) the way the rain dust deposits on the building fabric needs further considerations.

Due to the spherical curvature of the walls of the Jubilee Church, the deposits of rain dust are settled very differently from a standard vertical wall (Blocken, et al., 2013). On the curved concrete surface, the rain dust settles on the majority on the convex side, while the concave side, being sheltered from the rain, is barely affected by staining.

The survey also identified two sets of stains (Figure 4). The first set includes diffuse stained areas all over the convex side of the concrete surfaces directly affected by the rainwater. The second set, in contrast, includes localised stains occurring either by rain dripping indirectly from another building component or by soiling accumulated in specific points of the surface. This last group of stains is due more to construction defects rather than poor performance of the material. For instance, the rain drippings on the concave side of the top course of each shell are staining the concrete because a drip-edge flashing is missing. Therefore, the rain washes the top rows of ashlars only up to when the first horizontal joint trickles the water away down onto the portions of glass roofs. Localised long drippings of water are also notable on the concrete ashlars located in the proximity of the drop outlet of the gutters draining the portions of glass roof between the shells. These drop outlets deflect the rainwater directly on the concrete surface causing extensive stains visible near the connection between glass panels and concrete walls. Other localised long drippings stains marked the surface when dust accumulates within the bed joints between concrete blocks when they are not perfectly aligned. Generally, the rate of soiling at the building scale depends on a variety of factors such as atmospheric particle concentration, atmospheric particle size, colour of the particles relative to the colour of the surface, the roughness of the deposition surface (Grossi, et al., 2003). Furthermore, at the micro-scale, the cohesive forces between dust particles and the adhesive forces to a substrate are defined as gravity, molecular, electric, and capillary forces (Verhoef, 1988).

The second most evident alteration on the concrete surface of the Jubilee Church is caused by the additional coating painted in 2006 to increase the water repellence of the material. This previous maintenance work was tested out to resolve the issues of black staining that occurred already after three years from the opening of the church. The work consisted of high-pressure water-washing to remove the rain dust and a further layer of protective coat 
painted on the 64 bottom precast blocks to increase the hydrophobicity of the concrete. As declared by the Innovation Manager at the cement manufacturer, the product used was a silane and siloxane-based dispersing agent in water emulsion, which left a grey staining stripe along the bottom row of each shell.

The last set of stains are a greenish strip $150 \mathrm{~mm}$ high of biological contamination detected where the shells meet the ground. Due to the lack of linear gutter at the meeting point between each shell and ground pavement, this bottom area remains moist for longer creating the perfect conditions for biological growth.

\section{Results}

The specimens selected for this study are grouped into two sets. The first set of three samples consists of concrete splinters, 4 millimetres deep, chipped from the material surface in three different locations according to the different pathologies identified in the aerophotogrammetric survey.

The six specimens forming the second group are in the form of powder collected by rubbing the dust off the concrete surface in various locations selected according to the geometry of the sails and the area where the maintenance work occurred.

Overall the chemical analysis run on every sample confirmed that titanium dioxide $\left(\mathrm{TiO}_{2}\right)$ was added in the cement used for the Jubilee Church. Furthermore, all tests detected that titania particles consisted of both rutile and anatase crystallites (Luttrell, et al., 2014). The first splinter was removed from the concave side of Shell 3 where the material surface, sheltered by rain dust, still appears clean and smooth. The micro-Raman spectroscopy highlighted both components of the concrete, namely the aggregate of Carrara marble (named layer 1) and the cement (named layer 2) (Figure 5). As expected, for the aggregate (layer 1) calcite $\left[1748,1437,1086,712,282,155 \mathrm{~cm}^{-1}\right]$ was detected, while for the cement the result showed calcite $\left[1085,712 \mathrm{~cm}^{-1}\right]$ and anatase $\left[636,513,396,277,197,145 \mathrm{~cm}^{-1}\right]$ (Figure 6). This first outcome confirmed the use of $\mathrm{TiO}_{2}$ particles for the concrete as stated by the cement manufacturer.

A second splinter (sample 2) was flaked (Guerrini, 2018)where maintenance work was carried out to gather information on the paint used to increase the hydrophobicity of the concrete. The FTIR spectroscopy on this sample detected a superficial layer and a second, more internal, one (Figure 7 and Figure 8). The results detected calcite [636, 513, 396, 277 , 197, $\left.145 \mathrm{~cm}^{-1}\right]$, silicone compound [2963, 1262, 798, $\left.692 \mathrm{~cm}^{-1}\right], \mathrm{C}-\mathrm{S}-\mathrm{H}$ and dust $[3695,3619$, 
1006,$\left.914 ; 527,425 \mathrm{~cm}^{-1}\right]$ for the superficial layer, and calcite $[2516,1796,1414,873,711$ $\mathrm{cm}^{-1}$ ] (Figure 9) for the internal one. The finding of silicone compound confirmed the additional use of water repellent impregnant based on polymerized siloxanes. Beyond the detection of the additional paint, the micro-Raman spectroscopy of the superficial layer of sample 2 shows the presence of anatase $\left[636,513,395,196,144 \mathrm{~cm}^{-1}\right]$, calcite $[1747,1435$, 1086, $\left.712 \mathrm{~cm}^{-1}\right], \mathrm{C}-\mathrm{S}-\mathrm{H}$ and dust $\left[2973,2911,281 \mathrm{~cm}^{-1}\right]$. The same analysis run on the inner layer of sample 2 displays anatase $\left(\left[36,513,396,277,197,145 \mathrm{~cm}^{-1}\right]\right.$, calcite $\left[1085,712 \mathrm{~cm}^{-}\right.$ ${ }^{1}$ ]. Furthermore, the XRD highlighted anatase and calcite.

The third splinter was chipped from where the concrete surface meets the ground (sample 3). At the building scale, this area suffers from extensive blackening due to a lack of drainage system able to collect and keep the rainwater away from the shells. Raman spectroscopy on this fragment highlighted two layers (Figure 10) again. The FTIR spectroscopy of the outer layer shows calcite $\left[1749,1086,712,281,154 \mathrm{~cm}^{-1}\right], \mathrm{C}-\mathrm{S}-\mathrm{H}$ and dust $\left[1043 \mathrm{~cm}^{-1}\right]$ and, as it could be expected, a potential biological attack [2955, 2849, 1512, 1155, $\left.1001 \mathrm{~cm}^{-1}\right]$. The FTIR of the inner layer shows anatase $\left[636,513,396,280,196,143 \mathrm{~cm}^{-1}\right]$ and calcite $[1086$, $712 \mathrm{~cm}^{-1}$ ]. In more detail, the result of the XRD diffraction shows anatase, rutile, calcite, and clinozoisite (Figure 11).

Regarding the powders, four different specimens (samples 4, 5, 6 and 7) were rubbed off from the concrete surface where it is more affected by soiling (convex side). Furthermore, some dust within a concrete pore was analysed (sample 8) to understand how the porosity of the material may compromise the effectiveness of the titanium dioxide in terms of the selfcleaning property. Finally, to have a complete overview of the material behaviour, an additional sample (9) was rubbed off where the concrete surface appears smooth and clean (concave side).

The results on superficial powder sampled where the shells are heavily affected by soiling show the presence of calcite and silicate (sample 4, amber-grey coloured patina: calcite [1796, 1411, 873, $\left.711 \mathrm{~cm}^{-1}\right], \mathrm{C}-\mathrm{S}-\mathrm{H}$ and dust [1015, 537, $\left.432 \mathrm{~cm}^{-1}\right]$; sample 5, Figure 12, grey-coloured patina: calcite [1796, 1422, 874, $\left.712 \mathrm{~cm}^{-1}\right]$, C-S-H and dust [1010, 538, 428 $\left.\mathrm{cm}^{-1}\right]$; sample 6, black-grey coloured patina: calcite $\left[1796,1418,874,710 \mathrm{~cm}^{-1}\right], \mathrm{C}-\mathrm{S}-\mathrm{H}$ and dust $\left.\left[1005,536,424 \mathrm{~cm}^{-1}\right]\right)$. The results of the powder sampled in the proximity of the bottom layers of Shell 3 confirmed the use of silicone water-repellent, discussed with the Innovation Manager at the cement manufacturer, to increase the hydrophobicity of the surface (sample 7, 
Figure 13, grey-coloured patina: calcite $\left[2513,1796,1407,873,712 \mathrm{~cm}^{-1}\right]$, silicone polymer $\left[1260,1011 \mathrm{~cm}^{-1}\right], \mathrm{C}-\mathrm{S}-\mathrm{H}$ and dust $\left.\left[3696,3620,1028,915,799,533,469 \mathrm{~cm}^{-1}\right]\right)$.

The analysis of the content within a superficial concrete pore made visible by extensive blackening (sample 8) shows the same presence of calcite $\left[2514,1796,1405,873,712 \mathrm{~cm}^{-1}\right]$, C-S-H and dust $\left[1043,461 \mathrm{~cm}^{-1}\right]$ but with the addition of a potential biological attack [2960, 2881, $1729 \mathrm{~cm}^{-1}$ ] (Figure 14) as it could be expected (Chew \& Tan, 2003).

Sample 5 was analysed with XRD diffraction to acquire more detailed information and detect the crystalline phases within the powder. The results confirmed the presence of anatase $\left(\mathrm{TiO}_{2}\right)$, calcite, and detected the presence of clinozoisite, and huntite among the silicate minerals (Figure 12).

Where the concrete finish is not affected by rain dust (sample 9, Figure 15), the results show the same presence of calcite $\left[2511,1796,1412,712 \mathrm{~cm}^{-1}\right]$ and C-S-H $\left[1027,574,461 \mathrm{~cm}^{-1}\right]$.

The colourimetric measurements taken for this study in November 2018 describe colours of the external concrete surface turning towards darker tones. This is undoubtedly due to the presence of rain dust over most of the convex side of each shell. The data collected in 2018 were compared for each shell in Table 3, Table 4 and Table 5 with the measurement published by the cement manufacturer over the building period (the year 2000), the building completion time (September 2003), and in February 2005 and June 2006. Table 6 shows the impact of the weathering in the colour variations $\Delta \mathrm{E}^{*}$ between the completion of the building and 2018. The colour measurement on the concave and internal blocks showed less variation from the colour measured over the construction period, showing how the weathering and the building geometry of the walls affect the appearance of the white concrete.

The solar radiation on the convex, south-facing side of each shell is not even as some concrete blocks receive less natural light than others throughout the year (Figure 16). With more detail, Shell 1 is lit by Solar Irradiance between 1,021 - 2,210 KWh/m². Shell 2 receives between $0,148-2,314 \mathrm{KWh} / \mathrm{m}^{2}$ in a year with lowest Solar Irradiance where the shells are closer to each other (west side) and where Shell 1 overshadows Shell 2. Shell 3 receives between $0,123-2,323 \mathrm{KWh} / \mathrm{m}^{2}$. Like Shell 2, Shell 3 receives less sun radiation where the shells are closer to each other and where Shell 2 overshadows Shell 3. As expected, the concave, north-facing side is not irradiated by the sun, with values between 0,130 and 0,151 
$\mathrm{KWh} / \mathrm{m}^{2}$ for Shell 1; 0,153 and $0,123 \mathrm{KWh} / \mathrm{m}^{2}$ for Shell 2; and $0,161-0,124 \mathrm{KWh} / \mathrm{m}^{2}$ for Shell 3.

\section{Discussion}

The results gathered in this study helped to identify the causes of the current state of conservation of the photoactive concrete of the Jubilee Church in Rome. At the current stage, due to the rain dust deposit, it is impossible to understand if there is a relationship between colour variations and sun exposure for this building. As stated in the literature (Chew \& Conejos, 2017), self-cleaning façades with an east-west orientation might work better as they are exposed to a higher amount of sunlight intensity in comparison to those with a northsouth orientation as with the shells of the Jubilee Church. This lack of consideration in the relation of sun-path and catalytic effect of the surface is the outcome of the technical development of the building when the development of the material succeeded the design proposal.

Four factors inform the outcome of the chemical analysis and colour measurement: the verification of the statement of the cement manufacturer about the maintenance occurred in 2006; the presence of active titania particles on the concrete surface; the characterisation of the dust deposited on the shells; and the type of potential biological attack affecting the concrete.

First, the analysis of all the samples confirmed the content shared over the interview with the cement manufacturer, meaning the concrete surface was not lately integrated by additional layers of photocatalytic cement-based paint and therefore the results of this study refer to the original structure. Moreover, samples 2, 3 and 9 confirmed, as stated by concrete manufacturer, that the bottom of the shells was painted with a protective coat for increasing the water repellence of the concrete.

Regarding the photocatalytic activity of the concrete, the presence of anatase-crystal was detected in every superficial splinter analysed, despite the presence of rain dust or additional protective coating. Moreover, the anatase was also detected in the powder (sample 5) that was removed superficially from a concrete area heavily affected by rain dust. This demonstrates that $\mathrm{TiO}_{2}$ is still active. Therefore, washing away the accumulated dust may resume the photocatalytic effect of the concrete, eliminating the barrier to both reactants and photons and restabilising the removal of $\mathrm{NO}_{\mathrm{x}}$. 
The rain dust sampled on the convex side of the shells shows the presence of silica particles which cannot be oxidised by the titania particles within the cement. The presence of silicates in every powder specimen analysed is due to the typical characteristic of the pozzolanic dust particles typical of the area around Rome due to the volcanic origins (Gaddi, et al., 2017). In fact, the between $40 \%$ and $60 \%$ of the composition of pozzolanic dust in Italy is $\mathrm{SiO}_{2}$, following $\mathrm{Al}_{2} \mathrm{O}_{3}(14-30 \%) ; \mathrm{Fe}_{2} \mathrm{O}_{3}(6-25 \%) ; \mathrm{CaO}$ (2-12\%); $\mathrm{MgO}$ (1-4\%); alcali (2-12\%); $\mathrm{SO}_{3}$ $(0,2-0,8 \%) ; \mathrm{P}_{2} \mathrm{O}_{5}(0,05-0,5 \%) ; \mathrm{CO}_{2}$ (trace) (al-Swaidani, 2018). The silica particles detectable on the concave sides, however, are to be attributed to the cement showing a Characteristic Absorption (1000 cm-1) weaker than the samples from the convex surfaces. It can be argued that the hydrophilic photo-induced effect of the $\mathrm{TiO}_{2}$ could prevent the current state of decay by washing away pozzolanic dirt. However, the superficial abrasive erosion of the convex side of the concrete may have increased the mechanical bond significantly between the concrete and rain dust, reducing the hydrophily of the material. Products from the abrasive erosion, such as concrete dust, can be physically detected at the building scale all over the convex side of each shell. The concrete dust coming from the abrasion of the material and the pozzolanic dust from rainwater may then embody a physical barrier for UV-rays on the shells preventing the photocatalysis of the $\mathrm{TiO}_{2}$. This issue could also be confirmed by the repairing strategy tested out by the cement manufacturer based on increasing the hydrophilic of the material.

Finally, the results of samples 3 and 8 highlighted two kinds of potential biological attacks. The first one is localised along the stripe where the shells meet the ground and it is caused not by the material performance but mainly by a poorly designed construction detail lacking proper drainage system. The second potential biological attack is more diffuse, and it could lead to biodeterioration of the whole convex side of the shells. On that side, each concrete pore is continuously exposed to weathering, creating favourable conditions for organisms to grow. In this case, biodeterioration of concrete may happen by having elevated relative humidity, long cycles of humidification and drying, freezing and defrosting and, by being in urban atmospheres, high carbon dioxide concentrations (Wei, et al., 2013).

\section{Conclusion}

Only 16 years after the opening of the Jubilee Church, its three iconic shells are showing premature evidence of decay, indicating failure of the self-cleaning and colour-preserving properties of its exposed precast concrete. Through a mixed-mode research methodology, this 
study classified the material pathologies and linked them to possible causes in order to investigate why the appearance of the concrete is underperforming. Despite the current state of the material surface, presence of titanium dioxide in the form of anatase particles was detected by chemical analysis, demonstrating that the titanium dioxide is still active on the concrete surface. However, the self-cleaning characteristic of concrete with $\mathrm{TiO}_{2}$ performs only when both the sunlight promotes the redox of pollutant and the photo-induced hydrophilicity facilitates the façade cleansing. However, here, as the analysis reported, the hydrophilic effect is constrained by two main factors. The first one is related to the typical composition of the pozzolanic dust in Rome which cannot be oxidised by titania particles. The second one is the abrasive action of the rainwater on the spherical surface which enhances the superficial roughness of the concrete and therefore increases the bond between dust particles and concrete. The erosive phenomenon occurring on the convex surface is also supported by the colorimetric analysis showing a clear tendency towards whitish-grey hue due to the scattering of the natural light registered by the colorimeter.

The combination of the pozzolanic dust with the erosion products creates a patina that reduces even more the photocatalytic activity of the surface. This confirms what the literature states, namely that the efficiency of the $\mathrm{TiO}_{2}$ is strictly related to intrinsic characteristics of substrata where porosity can help water retention and roughness can favour the adhesion of dust to substrata (Graziani, et al., 2016) (Barberousse, et al., 2007) (Graziani, et al., 2013). The way the material is ageing is, then, strictly linked to the geometry of the sails where the concave side, rougher and with evidence of concrete dusting, is affected by diffuse soiling while the concave side presents still a smooth and white finish. In addition, although the decrease of photocatalytic effect for $\mathrm{TiO}_{2}$ caused by weathering is a well-known defect (Rudic, et al., 2015), the material performance evaluation of this case study revealed how the pozzolanic dust can significantly compromise the efficiency of the self-cleaning property.

Following the findings of this research, some recommendations can be made to reduce the frequency of the concrete washing for the Jubilee Church. First, the accumulation of rain dust deposited on the shells and the impact of the patina from biological contamination can be reduced by improving the construction details framing the sails. This can be achieved by building a drainage system where the sails meet the ground, by enclosing with a downcomer pipe the four drop outlets serving the glass roofs between the sails and by providing the top of each shell with aluminium flashing to shelter the highest course of the shells. Second, the self-cleaning property of the material can be improved by adding a layer of surface 
hydrophobic agents (Medeiros \& Paulo, 2008) on the sails to increase the water repellence of their convex - and more damaged - sides.

More generally, the outcome of this research shows that designers and engineers need to consider carefully how the rainwater washes the building fabric when the intention is to use concrete panels with self-cleaning properties. The way the rain washes the building not only can leave diffuse stains but more importantly compromise the material performance, and this is more relevant when considering the amount of computer-generated non-standard geometries recently implemented as architectural language. Moreover, joints depth and assembling precision are required to assure a perfect alignment of the panels avoiding gaps where dust can accumulate and therefore where localised soiling can happen.

Finally, due to the chemical composition and abrasive effect of pozzolanic dust, the selfcleaning properties of nanostructured titania particles can be compromised in countries where either the soil is predominantly distinguished by volcanic origins or when precipitations containing desert dust happen often. These environmental factors can increase the frequency of washing for the maintenance of the concrete panels compromising the aesthetic, economic and environmental advantages of adopting a self-cleaning material.

\section{Acknowledgment}

The author would like to express his acknowledgment to the Leverhulme Trust (UK) for funding the research project 'Our Future Heritage: Conservation Issues of Contemporary Architecture' which this paper stems from. The author would also like to thank the 'Ufficio Edilizia di Culto' (Estate Department) of the Roman Vicariate for supporting this research project; Gian Luca Guerrini for his generosity in sharing important information about the case study; Prof. Maria Laura Santarelli from the Department of Chemical Engineering of 'La Sapienza' University of Rome; Dr Elisabetta Giorgi from Department of Architectural Conservation of 'La Sapienza' University of Rome and BIM Engineer Enrico Cristini for providing the sun-study published in this paper.

\section{Funding}

This work was supported by the Leverhulme Trust [Research Fellowship, 2018]. 


\section{References}

al-Swaidani, A. M., 2018. Volcanic Scoria as Cement Replacement. In: G. Aiello, ed. Volcanoes Geological and Geophysical Setting, Theoretical Aspects and Numerical Modeling, Applications to. London: IntechOpen, pp. 211-237.

Anpo, M., Aikawa, N., Kodama, S. \& Kubokawa, Y., 1984. Photocatalytic Hydrogenation of Alkynes and Alkenes with Water over Titanium Dioxide. Hydrogenation Accompanied by Bond Fission. The Journal of Physical Chemistry, Volume 88, pp. 2569-2572.

Anpo, M. et al., 1985. Photoluminescence and Photocatalytic Activity of Highly Dispersed Titanium Oxide Anchored onto Porous Vycor Glass. The Journal of Physical Chemistry, Volume 89, pp. 50175021.

Baglione, C., 2003. Structural concept and construction of the Sails. Interview with Gennaro Guala. Casabella, Volume 715, pp. 20-27.

Ballari, M. M. \& Brouwers, H., 2013. Full Scale Demonstration of Air-Purifying Pavement. Journal of hazardous materials, Volume 254-255, p. 406-414.

Barberousse, H., Ruot, B., Yéprémian, C. \& Boulon, G., 2007. An assessment of façade coatings against colonisation by aerial algae and cyanobacteria. Building and Environment, Volume 42, p. $2555-2561$.

Barberousse, H., Ruot, C. \& Yepreman, C., 2007. An assessment of façade coatings against colonisation by aerial algae and cyanobacteria. Building and Environment, Volume 42, p. 2555-2561.

Blocken, B., Derome, D. \& Carmeliet, J., 2013. Rainwater runoff from building façades: a review. Building and Environment, Volume 60, pp. 339-361.

Brimblecombe, P. \& Grossi, C. M., 2004. The rate of darkening of material surfaces. In: S. Jimenez, ed. Air Pollution and Cultural Heritage. Rotterdam: AA Balkema Publishers, pp. 193-198.

Calia, A., Lettieri, M. \& Masieri, M., 2016. Durability assessment of nanostructured TiO2 coatings applied on limestones to enhance building surface with self-cleaning ability. Building and Environment, Volume 110, pp. 1-10.

Cardellicchio, L., 2018. On conservation issues of contemporary architecture: The technical design development and the ageing process of the Jubilee Church in Rome by Richard Meier. Frontiers of Architectural Research, 7(2), pp. 107-121.

Cardellicchio, L., 2018. Our Future Heritage. Ageing patterns of contemporary concrete: the case study of the Jubilee Church by Richard Meier in Rome.. Madrid, Eduardo Torroja Foundation, pp. 128-134.

Cedillo-González, E. I. et al., 2018. Influence of domestic and environmental weathering in the selfcleaning performance and durability of $\mathrm{TiO} 2$ photocatalytic coatings. Building and Environment, Volume 132, p. 96-103.

Chew, M. Y. \& Conejos, S., 2017. Green maintainability design criteria for nanostructured titanium dioxide (TiO2) façade coatings. International Journal of Building Pathology and Adaptation, 35(2), pp. 139-158.

Chew, M. Y. \& Tan, P. P., 2003. Staining of Façades. Singapore: World Scientific.

Diamanti, M. V. et al., 2015. Long term self-cleaning and photocatalytic performance of anatase added mortars exposed to the urban environment. Volume 96, pp. 270-278.

Falzetti, A., 2003. La Chiesa Dio Padre Misericordioso [The Jubilee Church]. Rome: Clear. 
Folli, A. et al., 2012. TiO2 photocatalysis in cementitious systems: insights into self-cleaning and depollution chemistry. Cement and Concrete Research, Volume 42, pp. 539-548.

Franklin, A., 2016. Journeys to the Guggenheim Museum Bilbao: Towards a revised Bilbao Effect. Annals of Tourism Research, Volume 59, pp. 79-92.

Fujishima, A., Hashimoto, K. \& Watanabe, T., 1999. TiO2 Photocatalysis: Fundamentals and Applications. Tokyo: BKC.

Fujishima, A. \& Zhang, X., 2006. Titanium Dioxide Photocatalysis: Present Situation and Future Approaches. Comptes Rendus Chimie, Volume 9, pp. 750-760.

Fujishima, A., Zhang, X. \& Tryk, D. A., 2008. TiO2 Photocatalysis and Related Surface Phenomena. Surface Science, Volume 63, pp. 515-582.

Gaddi, R. et al., 2017. Inquinamento atmosferico e beni culturali: effetti sui materiali a Roma [Air Pollution and Cultural Heritage: the effects on construction materials in Rome], Rome: ISPRA.

Gao, X. \& Wachs, I. E., 1999. Titania-Silica as Catalysts: Molecular Structural Characteristics and Physico-Chemical. Catalysis Today, Volume 51, pp. 233-254.

Genio Civile, 2018. Prezziario Unico del Cratere. Centro Italia [Construction Price Book, Central Italy]. Rome: DEI.

Graziani, L., Quagliarini, E., Bondioli, F. \& D'Orazio, M., 2014. Durability of self-cleaning TiO2 coatings on fired clay brick façades: effects of UV exposure and wet \& dry cycles. Building and Environment, Volume 71, p. 193-203.

Graziani, L., Quagliarini, E. \& D’Orazio, M., 2016. The role of roughness and porosity on the selfcleaning and anti-biofouling efficiency of $\mathrm{TiO} 2-\mathrm{Cu}$ and $\mathrm{TiO} 2-\mathrm{Ag}$ nanocoatings applied on fired bricks. Construction and Building Materials, Volume 129, p. 116-124.

Graziani, L., Quagliarini, E. \& D’Orazio, M., 2016. The role of roughness and porosity on the selfcleaning and anti-biofouling efficiency of $\mathrm{TiO} 2-\mathrm{Cu}$ and $\mathrm{TiO} 2-\mathrm{Ag}$ nanocoatings applied on fired bricks. Construction and Building Materials, Volume 129, p. 116-124.

Graziani, L. et al., 2013. Evaluation of inhibitory effect of TiO2 nanocoatings against microalgal growth on clay brick façades under weak UV exposure conditions. Building Environment, Volume 64, pp. 38-45.

Graziani, L. et al., 2013. Evaluation of inhibitory effect of TiO2 nanocoatings against microalgal growth on clay brick façades under weak UV exposure conditions. Building Environment, Volume 64, pp. 38-45.

Grossi, C. M., Esbert, R. M., Diaz-Pache, F. \& Alonso, F. J., 2003. Soiling of building stones in urban environments. Building and Environment, Volume 38, p. 147 - 159.

Guerrini, G. L., 2011. Case study: the Italcementi TX ACTIVE story. [Online]

Available at: https://www.scribd.com/document/370409737/Case-Study-the-Italcementi-TX-Active [Accessed 27 February 2018].

Guerrini, G. L., 2018. Personal Comunication [Interview] (27 September 2018).

Guerrini, G. L., Plassais, A., Pepe, C. \& Cassar, L., 2007. Use of photocatalytic cementitious materials for self-cleaning applications. Dresden, RILEM, pp. 219 - 226.

Guo, M. Z., Maury-Ramirez, A. \& Poon, C. S., 2016. Self-cleaning ability of titanium dioxide clear paint coated architectural mortar and its potential in field application.. Journal of Cleaner Production, Volume 112, p. 3583-3588. 
Hashimoto, K., Irie, H. \& Fujishima, A., 2005. TiO2 Photocatalysis: A Historical Overview and Future Prospects. Japanese Journal of Applied Physics, Volume 44, p. 8269.

Hassan, M. M., Dylla, H., Mohammad, L. N. \& Rupnow, T., 2010. Evaluation of the durability of titanium dioxide photocatalyst coating for concrete pavement. Construct. Build. Matter., Volume 24, p. $1456-1461$.

Hunger, M., Hüsken, G. \& Brouwers, H. J., 2010. Photocatalytic Degradation of Air PollutantsFrom Modeling to Large Scale Application. Cement and Concrete Research, Volume 40, pp. 313320.

Hüsken, G., Hunger, M. \& Brouwers, H., 2009. Experimental Study of Photocatalytic Concrete Products for Air.. Building and environment, Volume 44, pp. 2463-2474.

Hüsken, G., Hunger, M. \& Brouwers, H. J., 8-9 October 2007. Comparative Study on Cementitious Products Containing Titanium. Bagneux, RILEM, pp. 47-154.

Linsebigler, A. L., Lu, G. \& Yates, J. T., 1995. Photocatalysis on TiO2 Surfaces: Principles, Mechanisms, and Selected. Chemical Reviews, Volume 95, pp. 735-758.

Luttrell, T. et al., 2014. Why is anatase a better photocatalyst than rutile? - Model studies on epitaxial TiO2 films. Scientific Reports, 4(4043), pp. 1-8.

Lyall, S., 2004. Using the power of divine prefabrication. Concrete quarterly, Volume 207, pp. 4-6.

Medeiros, M. \& Paulo, H., 2008. Efficacy of surface hydrophobic agents in reducing water and chloride ion penetration in concrete. Materials and Structures, pp. 59-71.

Mornati, S., 2017. The contribution of Italian Engineering in the design and construction of the Jubilee Church by Richard Meier (1996-2003). Cambridge, Cambridge Press, pp. 469-479.

Rudic, O. et al., 2015. Investigation of the durability of porous mineral substrates with newly designed TiO2-LDH coating. Ceramics International, 41(8), pp. 9779-9792.

Sassoni, E. et al., 2018. Durable self-cleaning coatings for architectural surfaces by incorporation of TiO2 nano-particles into hydroxyapatite films. Materials, 11(177).

Tee, S. P., Shibata, T., Irie, H. \& Hashimoto, K., 2005. Photo-induced wettability control on TiO2 Surface. Electrochem, Volume 8, pp. 23-25.

Turchi, C. S. \& Ollis, D. F., 1990. Photocatalytic Degradation of Organic Water Contaminants: Mechanisms Involving. Journal of catalysis, 122(http://dx.doi.org/10.1016/0021-9517(90)90269-P), pp. 178-192.

UNI EN 15886, 2010. Conservation of Cultural Property - Test Methods - Colour Measurement of Surface. Official Italian Version of UNI EN 15886:2010. Milan: UNI.

Verhoef, L. G. W. ed., 1988. The Soiling and Cleaning of Building Façades. London: Routledge.

Wang, R. et al., 1997. Light-induced amphiphilic surfaces. Nature, Volume 338, p. 431-432.

Wei, S. et al., 2013. Microbiologically induced deterioration of concrete - A Review. Braz J Microbiol., 44(4), p. 1001-1007.

Zhang, L., Zhang, P. \& Chen, S., 2007. Influence of pretreatment of titanium substrate on long-term stability of TiO2 film. Chinese Journal of Catalysis, Volume 28, p. 299-306. 
